\title{
ACE gene polymorphism is associated with COPD and COPD with pulmonary hypertension: a meta-analysis
}

This article was published in the following Dove Press journal: International Journal of COPD

\author{
Yao Ma ${ }^{1, *}$ \\ Xiang Tong ${ }^{2, *}$ \\ Ying Liu' \\ Sitong $\mathrm{Liu}^{2}$ \\ Hai Xiong ${ }^{3}$ \\ Hong Fan ${ }^{2}$ \\ 'The Center of Gerontology and \\ Geriatrics, West China Hospital/ \\ West China School of Medicine, \\ Sichuan University, Chengdu, Sichuan \\ 6I004I, People's Republic of China; \\ ${ }^{2}$ Department of Respiratory and \\ Critical Care Medicine, West China \\ Hospital/West China School of \\ Medicine, Sichuan University, Chengdu, \\ Sichuan 6I004I, People's Republic of \\ China; ${ }^{3}$ Department of Gerontology, \\ No 4 West China Teaching Hospital, \\ Sichuan University, Chengdu, Sichuan \\ 6I004I, People's Republic of China \\ *These authors contributed equally \\ to this work
}

Purpose: Angiotensin-converting enzyme $(A C E)$ gene I/D polymorphism has been studied in relation to the susceptibility to COPD and COPD with pulmonary hypertension (PH) with inconclusive results. We performed the first comprehensive meta-analysis to evaluate accurately the association between the $A C E$ gene polymorphism and the risk of COPD.

Methods: Data were analyzed using odds ratios (ORs) and the corresponding $95 \%$ CIs to measure the strength of the models. Subgroup analyses were conducted by ethnicity and complication which referred to $\mathrm{PH}$.

Results: In total, 15 studies (2,635 participants) were included in our study, of which four studies (288 participants) were for PH subgroup. The overall analysis results indicated that the $A C E$ gene polymorphism was not associated with COPD susceptibility in all gene models. However, the ethnic subgroup analysis results indicated that $A C E$ gene polymorphism was associated with Asians' susceptibility to COPD (DD+DI vs II, OR=1.47, $P=0.019,95 \% \mathrm{CI}$ : 1.07-2.02). Further, the overall results of the present study detected no statistical significance between $A C E$ gene polymorphism and the risk of COPD with $\mathrm{PH}$, but the homozygote variant (DD) increased the risk of PH in Asian COPD patients (DD vs ID+II, OR=2.05, $P=0.05,95 \%$ CI: $1.00-4.19$ ). Conclusion: The current study suggests that $A C E$ polymorphism, particularly the homozygote variant (DD), might contribute to the risk of COPD and COPD with PH among Asians. Further studies with larger sample size and more ethnicities are expected to be conducted in the future to validate the results.

Keywords: ACE, COPD, pulmonary hypertension, polymorphism, susceptibility, meta-analysis

\section{Introduction}

COPD, a serious global health problem with a high burden on health care resources, is a leading cause of morbidity and mortality worldwide and is predicted to be the third leading cause of death worldwide by the year 2020. ${ }^{1-4}$ Some COPD patients face pulmonary hypertension $(\mathrm{PH})$ and right heart failure. However, the precise mechanism of this disease and the progression of $\mathrm{PH}$ among COPD patients are not fully understood. ${ }^{5}$ Studies have shown that smoking is the most important exogenous risk factor, and other risk factors include exposure to environmental and occupational polycyclic aromatic hydrocarbons. ${ }^{6,7}$ Nevertheless, only $20 \%$ of long-term smokers develop COPD and $30 \%$ lifetime nonsmokers also suffer from COPD,${ }^{8,9}$ which suggests that genetic background plays an important role in development of COPD. Moreover, the differences in clinical presentation and severity of the disease between racial and ethnic groups indicate a significant genetic predisposition to the disease. ${ }^{10}$ Thus, different polymorphisms in potential candidate genes for the development or course of COPD have been
Department of Respiratory and Critical Care Medicine, West China Hospital/ West China School of Medicine, Sichuan University, Guoxuexiang 37, Chengdu, 61004I, Sichuan, People's Republic of China

Tel/fax +862885423520

Email fanhongfan@qq.com (c) (1) (5) $2018 \mathrm{Ma}$ et al. This work is published and licensed by Dove Medical Press Limited. The full terms of this license are available at https://www.dovepress.com/terms.php
and incorporate the Creative Commons Attribution - Non Commercial (unported, v3.0) License (http://creativecommons.org/licenses/by-nc/3.0/). By accessing the work you

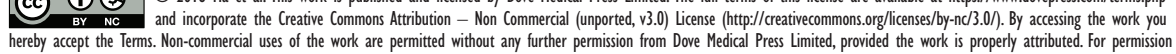
for commercial use of this work, please see paragraphs 4.2 and 5 of our Terms (https://www.dovepress.com/terms.php). 
detected. $\alpha 1$-Antitrypsin deficiency, the only genetic factor identified so far in predisposing individuals to COPD, affects only minority number of patients, and hence it suggests the existence of a polygenic fixed susceptibility. ${ }^{11}$

The development of COPD and PH in COPD patients is associated with the activation of the renin-angiotensinaldosterone system (RAAS), which influences pulmonary vasoconstriction and pulmonary vascular remodeling. 5,7,12 Angiotensin-converting enzyme (ACE), a zinc metallopeptidase highly expressed in the lungs and degrading bradykinin, catalyzes the formation of the Angiotensin $\mathrm{II}^{11}$ and plays an important role in RAAS. It is a powerful vasoconstrictor, inflammatory modulator, and cellular growth factor. ${ }^{13}$ Thus, the $A C E$ gene has been considered as a contributor to the development of COPD and PH in COPD patients. ${ }^{5}$

The $A C E$ gene is located in chromosome $17 \mathrm{q} 23$, and it contains a polymorphism based on the presence (insertion [I]) or absence (deletion [D]) of a 287-bp nonsense domain in intron 16, resulting in three different genotypes (II, ID, and DD). ${ }^{5,7}$ The $A C E$ DD genotype is associated with higher circulating and tissue ACE concentration and, therefore, increased activity. ${ }^{13}$ Lower ACE activity is likely to be beneficial to patients in the long-term course of COPD. ${ }^{14}$ A previous study has indicated that the DD genotype is increased in patients with acute adult respiratory distress syndrome (ARDS) and is associated with a higher mortality in the ARDS group. ${ }^{7}$ D-allele carrier status or DD genotype is associated with smokers and their increased risk of developing COPD. ${ }^{11}$ On the contrary, the $A C E$ I allele may be associated with a stable course of COPD with less hospital admissions. ${ }^{7}$ However, some studies have reported apparently conflicting results, ${ }^{15-17}$ and because of the small sample size of each study, they possibly lacked sufficient power to assess the true value. So far, whether the $A C E$ gene polymorphism is associated with the risk of COPD and COPD with PH has not been systematically assessed.

In the study, we performed a meta-analysis to accurately evaluate the effect of $A C E$ gene polymorphism on susceptibility to COPD and COPD with PH. To our knowledge, this is the most recent and comprehensive meta-analysis to assess the relationship to date.

\section{Methods}

\section{Literature search}

We performed a literature search in PubMed, Embase, Wanfang Database, and China National Knowledge Infrastructure (CNKI), covering all studies published up to 17 March 2018, using the search keywords "angiotensin-converting enzyme,
ACE, polymorphism, chronic obstructive pulmonary disease, COPD, pulmonary hypertension, $\mathrm{PH}$ ", as well as combinations of these terms. All eligible studies were retrieved, and their bibliographies were checked for other relevant publications. The studies published in English or Chinese were included. Additionally, we also conducted a web-based search using a variety of commercial Internet search engines (such as Google and Baidu), using the same technique. Only published studies with full-text articles were included. If studies had partially overlapped samples, only the most recent or complete study was selected.

\section{Study selection}

We included studies that met the following criteria: (a) published in English or in Chinese and (b) with a casecontrol study design, (c) that supply the available genotype frequencies in cases and controls and (d) with available data for calculating odds ratio (OR) and $95 \%$ CI provided in the primary study, and (e) that involved human subjects as the main object of study. Studies were excluded if they come under the following criteria: (a) lacking a control cohort, (b) being a review and overlapping study, and (c) not showing the available data or other essential information.

\section{Quality-score evaluation}

The quality of the included studies was assessed according to the Newcastle-Ottawa scale (case-control study). The scale to estimate the quality was based on three aspects, including selection, comparability, and exposure in the primary study. The total scores ranged from 0 to $9(0-3,4-6$, and 7-9 indicated low, moderate, and high quality, respectively).

\section{Data extraction}

Two of the authors (Yao Ma and Xiang Tong) independently collected detailed information and data from each study using a predesigned data extraction Excel form. If there were a disagreement, the third author (Ying Liu) would estimate these articles. The information and data extracted included first author, publication year, country, ethnicity of study population, case and control group size, age of the participant, genotype and allele distribution, and test method.

\section{Statistical methods}

In the present study, the OR and 95\% CI were used to investigate the strength of the association effect between $A C E$ gene polymorphism and COPD susceptibility. The Hardy-Weinberg equilibrium was tested by using the $\chi^{2}$ test in each control group before performing the meta-analysis. 
We calculated the heterogeneity by using the $\chi^{2}$-based $Q$-test and $I^{2}$ statistic tests. The pooled effect size (OR) would be assessed by using the random-effect model if the heterogeneity was considered statistically significant $\left(I^{2}>50 \%\right.$ and $\left.P<0.10\right)$; if not, the fixed-effect model was used. To evaluate the ethnicity-specific effects, we also performed subgroup analyses considering different specific effects.

In addition, publication bias was assessed using several methods. Visual inspection of asymmetry in funnel plots was carried out, and the Begg's and Egger's tests were used to assess further the publication bias. All data analyses were conducted using the STATA 12.0 software.

\section{Results}

\section{Study characteristics}

Initially, we performed a search in PubMed, Embase, Wanfang Database, and CNKI and identified 66 articles (Figure 1). We rejected and removed 35 articles because they were repeated studies. Eight articles were excluded after reading the titles and abstracts. Two articles were excluded because they were not relevant to COPD or/and risk of PH in COPD in relation to the $A C E$ gene polymorphism. Two other articles were eliminated because they were reviews. One study was rejected because it was an animal experiment, and another article was not included in the meta-analysis because it was not designed as a case-control study. Finally, we confirmed 15 eligible studies ( 1,279 cases and 1,356 controls $)^{7,10,11,13,15-25}$ for the COPD subgroup and four studies for the PH subgroup, and we included them in the current meta-analysis. Twelve articles were in English, ${ }^{7,10,11,13,15-20,23,25}$ and three were in Chinese. ${ }^{21,22,24}$ Among these studies, five were conducted in Asians and ten in Caucasians. Additionally, according to the quality-score evaluation, six articles were of moderate quality, and the others were of high quality. The characteristics of the collected studies are listed in Tables 1 and 2.

\section{Association between ACE gene polymorphism and COPD}

In total, 15 studies (1,279 cases and 1,356 controls) reported the association between $A C E$ gene polymorphism and COPD susceptibility. The evaluation of the association between $A C E$ gene polymorphism and COPD risk is shown in Table 3. Overall, the results indicated that there were no significant associations between COPD risk and D allele, compared to that with I allele. In addition, the overall analysis results indicated that the $A C E$ gene polymorphism was not associated with COPD susceptibility in all gene models (Figure 2). However, we found a significant heterogeneity between studies in the meta-analysis, and we executed a sensitivity analysis by sequentially excluding studies from the meta-analysis to investigate the influence of each study on the pooled results. The results of sensitivity analysis found that the pooled OR was not significantly altered (Figure 3). Therefore, we further carried out a subgroup analysis, and the results indicated that DD

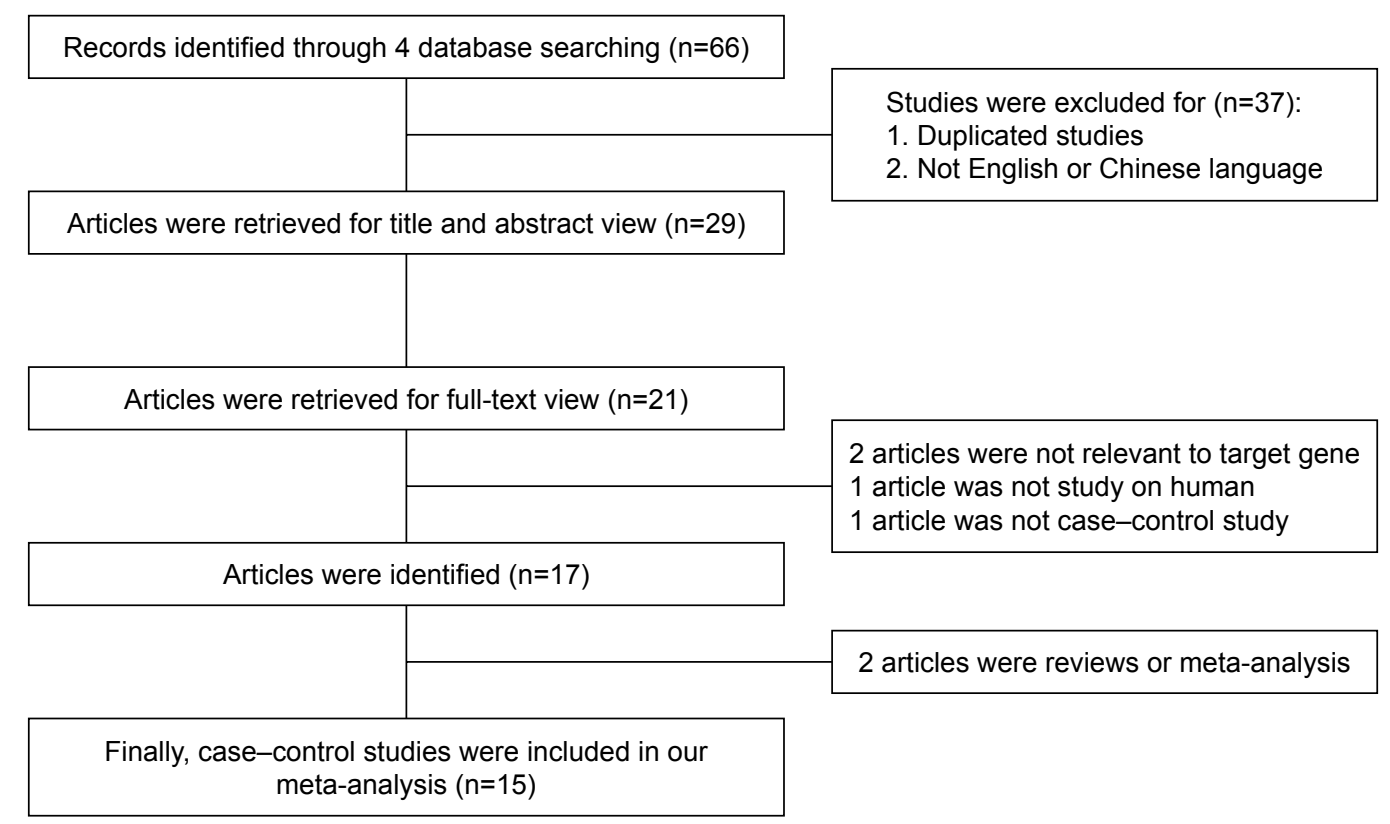

Figure I The flow diagram of included and excluded studies. 
Table I Characteristics of case-control studies included in the meta-analysis

\begin{tabular}{|c|c|c|c|c|c|c|c|}
\hline \multirow[t]{2}{*}{ Study } & \multirow[t]{2}{*}{ Year } & \multirow[t]{2}{*}{ Country } & \multirow[t]{2}{*}{ Ethnicity } & \multirow[t]{2}{*}{ Cases/controls } & Age & Method & \multirow{2}{*}{$\begin{array}{l}\text { Q } \\
\text { score }\end{array}$} \\
\hline & & & & & \multicolumn{2}{|l|}{ Case/control } & \\
\hline \multicolumn{8}{|l|}{ COPD } \\
\hline Ahsan et al ${ }^{10}$ & 2004 & India & Asian & $27 / 66$ & NA & PCR-RFLP & 7 \\
\hline Ayada et $\mathrm{al}^{20}$ & 2014 & Turkey & Caucasian & $47 / 64$ & NA & PCR-RFLP & 6 \\
\hline Busquets et al" & 2007 & Spain & Caucasian & $74 / 159$ & $62 \pm 2 / \mathrm{NA}$ & PCR-RFLP & 8 \\
\hline Gu et $\mathrm{al}^{22}$ & 2003 & China & Asian & $122 / 159$ & $60.8 / 63.5$ & PCR-RFLP & 5 \\
\hline Hopkinson et $\mathrm{al}^{13}$ & 2004 & England & Caucasian & $103 / 101$ & $64.1 \pm 9.1 / 61.8 \pm 8.6$ & PCR-RFLP & 7 \\
\hline Jiang and Zhang ${ }^{24}$ & 2002 & China & Asian & $60 / 30$ & $34-80 / 35-78$ & PCR-RFLP & 5 \\
\hline Kuzubova et al ${ }^{18}$ & 2013 & Russia & Caucasian & $63 / 95$ & $60.4 \pm 1.0 / 57.3 \pm 1.7$ & PCR-RFLP & 8 \\
\hline Mlak et $\mathrm{al}^{25}$ & 2016 & Poland & Caucasian & $206 / 165$ & $63 \pm 9.4 / 64 \pm 10.6$ & PCR-RFLP & 8 \\
\hline Pabst et $\mathrm{al}^{7}$ & 2009 & Germany & Caucasian & $152 / 158$ & $62.8 \pm 11.1 / 63.9 \pm 18.4$ & PCR-RFLP & 7 \\
\hline Simsek et al ${ }^{19}$ & 2013 & Turkey & Caucasian & $66 / 40$ & $61.23 \pm 11.41 / 59.17 \pm 11.23$ & PCR-RFLP & 7 \\
\hline Tkácová et al ${ }^{17}$ & 2005 & Slovakia & Caucasian & $66 / 118$ & $65.4 \pm 2.5 / 63.5 \pm 1.2$ & PCR-RFLP & 7 \\
\hline Ulasli et $\mathrm{al}^{16}$ & 2013 & Turkey & Caucasian & $80 / 49$ & $65.1 \pm 7.60 / 54.6 \pm 7.8$ & PCR-RFLP & 6 \\
\hline $\mathrm{Xu}^{21}$ & 2002 & China & Asian & $110 / 55$ & $69.66 \pm 6.60 / 68.86 \pm 11.02$ & PCR-RFLP & 5 \\
\hline Yildiz et al ${ }^{15}$ & 2003 & Turkey & Caucasian & $42 / 40$ & $62 \pm 7 / 60 \pm 8$ & PCR-RFLP & 7 \\
\hline Zhang et $\mathrm{al}^{23}$ & 2008 & China & Asian & $61 / 57$ & $63.8 \pm 8.2 / 61.6 \pm 7.3$ & PCR-RFLP & 6 \\
\hline \multicolumn{8}{|l|}{$\mathrm{PH}$} \\
\hline Jiang and Zhang ${ }^{24}$ & 2002 & China & Asian & $30 / 30$ & $50-80 / 35-78$ & PCR-RFLP & 5 \\
\hline Ulasli et al ${ }^{16}$ & 2013 & Turkey & Caucasian & $30 / 50$ & $66.9 \pm 7.2 / 54.6 \pm 7.8$ & PCR-RFLP & 6 \\
\hline $\mathrm{Xu}^{21}$ & 2002 & China & Asian & $57 / 53$ & $70.02 \pm 8.21 / 68.86 \pm 11.02$ & PCR-RFLP & 5 \\
\hline Yildiz et $\mathrm{al}^{15}$ & 2003 & Turkey & Caucasian & $24 / 14$ & $62 \pm 4.8 / 60 \pm 8$ & PCR-RFLP & 6 \\
\hline
\end{tabular}

Abbreviations: $\mathrm{PH}$, pulmonary hypertension; NA, not available; PCR-RFLP, polymerase chain reaction-restriction fragment length polymorphism.

Table 2 Distributions of ACE allele and genotypes in different studies' susceptibility to COPD

\begin{tabular}{|c|c|c|c|c|c|c|c|c|c|c|c|c|c|}
\hline \multirow[t]{2}{*}{ Study } & \multirow[t]{2}{*}{ Language } & \multirow[t]{2}{*}{ Year } & \multicolumn{5}{|c|}{ COPD } & \multicolumn{5}{|c|}{ Control } & \multirow[t]{2}{*}{ HWE } \\
\hline & & & DD & ID & II & D & $\mathbf{I}$ & DD & ID & II & D & $\mathbf{I}$ & \\
\hline \multicolumn{14}{|l|}{ COPD } \\
\hline Ahsan et al ${ }^{10}$ & English & 2004 & 5 & 12 & 10 & 22 & 32 & 10 & 31 & 23 & 51 & 77 & 0.93 \\
\hline Ayada et $\mathrm{al}^{20}$ & English & 2014 & 13 & 26 & 8 & 52 & 42 & 28 & 28 & 8 & 84 & 44 & 0.81 \\
\hline Busquets et al'" & English & 2007 & 27 & 40 & 7 & 94 & 54 & 53 & 79 & 27 & 185 & 133 & 0.79 \\
\hline Gu et $\mathrm{al}^{22}$ & Chinese & 2003 & 57 & 37 & 28 & $15 \mid$ & 93 & 25 & 85 & 49 & 135 & 183 & 0.24 \\
\hline Hopkinson et al ${ }^{13}$ & English & 2004 & 25 & 49 & 29 & 99 & 107 & 24 & 49 & 28 & 97 & 105 & 0.78 \\
\hline Jiang and Zhang ${ }^{24}$ & Chinese & 2002 & 24 & 20 & 16 & 68 & 52 & 5 & 10 & 15 & 20 & 40 & 0.17 \\
\hline Kuzubova et al ${ }^{18}$ & English & 2013 & 17 & 29 & 17 & 63 & 63 & 22 & 49 & 24 & 93 & 97 & 0.75 \\
\hline Mlak et $\mathrm{a}^{25}$ & English & 2016 & 60 & 99 & 47 & 219 & 199 & 51 & 73 & 41 & 175 & 155 & 0.15 \\
\hline Pabst et $\mathrm{al}^{7}$ & English & 2009 & 33 & 76 & 43 & 142 & 162 & 50 & 69 & 39 & 169 & 147 & 0.12 \\
\hline Simsek et al ${ }^{19}$ & English & 2013 & 31 & 20 & 15 & 82 & 50 & 13 & 19 & 8 & 45 & 35 & 0.83 \\
\hline Tkácová et al ${ }^{17}$ & English & 2005 & 20 & 31 & 15 & 7I & 61 & 31 & 68 & 19 & 130 & 106 & 0.07 \\
\hline Ulasli et $\mathrm{al}^{16}$ & English & 2013 & 47 & 17 & 16 & 111 & 49 & 33 & 10 & 6 & 76 & 22 & 0.003 \\
\hline $\mathrm{Xu}^{21}$ & Chinese & 2002 & 22 & 56 & 32 & 100 & 120 & 7 & 25 & 23 & 39 & 71 & 0.96 \\
\hline Yildiz et al ${ }^{15}$ & English & 2003 & 14 & 21 & 7 & 49 & 35 & 12 & 18 & 10 & 42 & 38 & 0.54 \\
\hline \multirow[t]{2}{*}{ Zhang et $\mathrm{al}^{23}$} & Chinese & 2008 & 13 & 27 & 21 & 53 & 69 & 9 & 28 & 20 & 46 & 68 & 0.88 \\
\hline & & & \multicolumn{5}{|c|}{ COPD with PH } & \multicolumn{6}{|c|}{ COPD without PH } \\
\hline \multicolumn{14}{|l|}{$\mathrm{PH}$} \\
\hline Jiang and Zhang ${ }^{24}$ & Chinese & 2002 & 13 & 8 & 9 & 34 & 26 & 11 & 12 & 7 & 34 & 26 & NA \\
\hline Ulasli et a ${ }^{16}$ & English & 2013 & 19 & 6 & 5 & 44 & 16 & 28 & 11 & 11 & 67 & 33 & NA \\
\hline $\mathrm{Xu}^{21}$ & Chinese & 2002 & 16 & 25 & 16 & 57 & 57 & 6 & 31 & 16 & 43 & 63 & NA \\
\hline Yildiz et al ${ }^{15}$ & English & 2003 & 7 & \multicolumn{2}{|c|}{17} & NA & NA & 4 & \multicolumn{2}{|c|}{10} & NA & NA & NA \\
\hline
\end{tabular}

Abbreviations: ACE, angiotensin-converting enzyme; HWE, Hardy-Weinberg equilibrium; PH, pulmonary hypertension; NA, not available. 
Table 3 Summary of total results and subgroup analysis from different comparative genetic models

\begin{tabular}{|c|c|c|c|c|c|c|c|c|c|c|c|c|}
\hline \multirow{2}{*}{$\begin{array}{l}\text { Genetic } \\
\text { models }\end{array}$} & \multicolumn{6}{|l|}{ COPD } & \multicolumn{6}{|c|}{ COPD+PH } \\
\hline & $\mathbf{N}^{\mathrm{a}}$ & OR & $95 \% \mathrm{Cl}$ & P-value & Models & $I^{2}(\%)$ & $\mathbf{N}^{\mathbf{a}}$ & OR & $95 \% \mathrm{Cl}$ & $P$-value & Models & $I^{2}(\%)$ \\
\hline \multicolumn{13}{|l|}{ DD+ID vs II } \\
\hline Overall & $15^{7,10,11,13,15-25}$ & 1.10 & $0.90-1.34$ & 0.34 & Fixed & 17.3 & $3^{16,21,24}$ & 1.05 & $0.59-1.89$ & 0.86 & Fixed & 0 \\
\hline Asians & $5^{10,21-24}$ & 1.48 & $1.07-2.03$ & 0.02 & Fixed & 0 & $2^{21,24}$ & 0.95 & $0.49-1.86$ & 0.89 & Fixed & 0 \\
\hline Caucasians & $10^{7,11,13,15-20,25}$ & 0.92 & $0.71-1.18$ & 0.49 & Fixed & 0 & $1^{16}$ & $\mathrm{I} .4 \mathrm{I}$ & $0.44-4.55$ & 0.57 & Fixed & 0 \\
\hline \multicolumn{13}{|l|}{ DD vs DI+II } \\
\hline Overall & $15^{7,10,11,13,15-25}$ & 1.27 & $0.88-1.82$ & 0.21 & Random & 69.6 & $4^{15,16,21,24}$ & 1.64 & $0.97-2.78$ & 0.07 & Fixed & 0 \\
\hline Asians & $5^{10,21-24}$ & 2.36 & $1.32-4.22$ & 0.004 & Random & 51.8 & $2^{21,24}$ & 2.05 & $1.00-4.19$ & 0.05 & Fixed & 21.0 \\
\hline Caucasians & $10^{7,11,13,15-20,25}$ & 0.93 & $0.74-1.16$ & 0.52 & Fixed & 26.6 & $2^{15,16}$ & 1.25 & $0.57-2.74$ & 0.57 & Fixed & 0 \\
\hline \multicolumn{13}{|l|}{ DD vs II } \\
\hline Overall & $15^{7,10,11,13,15-25}$ & 1.28 & $0.86-1.90$ & 0.22 & Random & 58.4 & $3^{16,21,24}$ & 1.60 & $0.80-3.18$ & 0.19 & Fixed & 0 \\
\hline Asians & $5^{10,21-24}$ & 2.68 & $1.76-4.08$ & 0.000 & Fixed & 25.9 & $2^{21,24}$ & 1.65 & $0.7 I-3.83$ & 0.24 & Fixed & 31.6 \\
\hline Caucasians & $10^{7,11,13,15-20,25}$ & 0.89 & $0.66-1.20$ & 0.44 & Fixed & 5.7 & $1^{16}$ & 1.49 & $0.45-4.99$ & 0.52 & Fixed & 0 \\
\hline \multicolumn{13}{|l|}{ DI vs II } \\
\hline Overall & $15^{7,10,11,13,15-25}$ & 0.99 & $0.80-1.22$ & 0.91 & Fixed & 0 & $3^{16,21,24}$ & 0.79 & $0.4 I-I .50$ & 0.47 & Fixed & 0 \\
\hline Asians & $5^{10,21-24}$ & 1.07 & $0.75-|.5|$ & 0.71 & Fixed & 0 & $2^{21,24}$ & 0.71 & $0.34-1.46$ & 0.35 & Fixed & 0 \\
\hline Caucasians & $10^{7,11,13,15-20,25}$ & 0.94 & $0.72-1.23$ & 0.66 & Fixed & 0 & $1^{16}$ & 1.20 & $0.28-5.12$ & 0.81 & Fixed & 0 \\
\hline \multicolumn{13}{|l|}{ D vs I } \\
\hline Overall & $15^{7,10,11,13,15-25}$ & I. 14 & $0.91-1.41$ & 0.25 & Random & 66.2 & $3^{16,21,24}$ & 1.30 & $0.90-1.87$ & 0.16 & Fixed & 0 \\
\hline Asians & $5^{10,21-24}$ & 1.63 & $1.17-2.27$ & 0.004 & Random & 54.0 & $2^{21,24}$ & 1.28 & $0.83-1.96$ & 0.26 & Fixed & 0 \\
\hline Caucasians & $10^{7,11,13,15-20,25}$ & 0.94 & $0.81-1.09$ & 0.41 & Fixed & 18.9 & $1^{16}$ & 1.35 & $0.67-2.75$ & 0.40 & Fixed & 0 \\
\hline
\end{tabular}

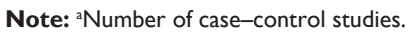

Abbreviations: $\mathrm{PH}$, pulmonary hypertension; OR, odds ratio.

homozygous genotype was significantly associated with codominant model (DD vs II, OR=2.68, $P<0.001,95 \% \mathrm{CI}$ : COPD in dominant model (DD+DI vs II, $\mathrm{OR}=1.47, P=0.019, \quad 1.76-4.08$; Figure 6), and allele model ( $\mathrm{D}$ vs I, OR=1.62, 95\% CI: 1.07-2.02; Figure 4), recessive model (DD vs $P=0.005,95 \%$ CI: 1.16-2.27; Figure 7), but this was not DI+II, OR=2.38, $P=0.003,95 \%$ CI: 1.34-4.22; Figure 5), true in Caucasians. Funnel plots were almost symmetrical

\begin{tabular}{|c|c|c|}
\hline Study ID & OR (95\% Cl) & $\%$ weight \\
\hline Ahsan et $\mathrm{al}^{10}$ & $0.91(0.36-2.31)$ & 4.21 \\
\hline Ayada et $\mathrm{al}^{20}$ & $0.70(0.24-2.01)$ & 3.68 \\
\hline Busquets et al ${ }^{11}$ & $1.96(0.81-4.73)$ & 3.61 \\
\hline Gu et $a^{22}$ & $1.50(0.87-2.57)$ & 9.99 \\
\hline Hopkinson et $\mathrm{al}^{13}$ & $0.98(0.53-1.80)$ & 9.45 \\
\hline Jiang and Zhang ${ }^{24}$ & $2.75(1.10-6.88)$ & 2.43 \\
\hline Kuzubova et al ${ }^{18}$ & $0.91(0.44-1.89)$ & 6.96 \\
\hline Mlak et $\mathrm{al}^{25}$ & $1.12(0.69-1.81)$ & 14.31 \\
\hline Pabst et $\mathrm{al}^{7}$ & $0.83(0.50-1.38)$ & 15.04 \\
\hline Simsek et $\mathrm{al}^{19}$ & $0.85(0.32-2.23)$ & 4.13 \\
\hline Tkácová et al ${ }^{17}$ & $0.65(0.31-1.39)$ & 7.35 \\
\hline Ulasli et al ${ }^{16}$ & $0.56(0.20-1.54)$ & 4.86 \\
\hline $\mathrm{Xu}^{21}$ & $1.75(0.89-3.44)$ & 5.65 \\
\hline Yildiz et al ${ }^{15}$ & $1.67(0.56-4.92)$ & 2.33 \\
\hline Zhang et $\mathrm{al}^{23}$ & $1.03(0.48-2.20)$ & 6.00 \\
\hline Overall $\left(I^{2}=9.2 \%, P=0.350\right)$ & $1.10(0.92-1.32)$ & 100 \\
\hline
\end{tabular}

Figure 2 Overall results of association between ACE gene polymorphism and COPD risk (DD+DI vs II). Abbreviations: $A C E$, angiotensin-converting enzyme; OR, odds ratio. 


\section{Meta-analysis estimates, given named study is omitted}

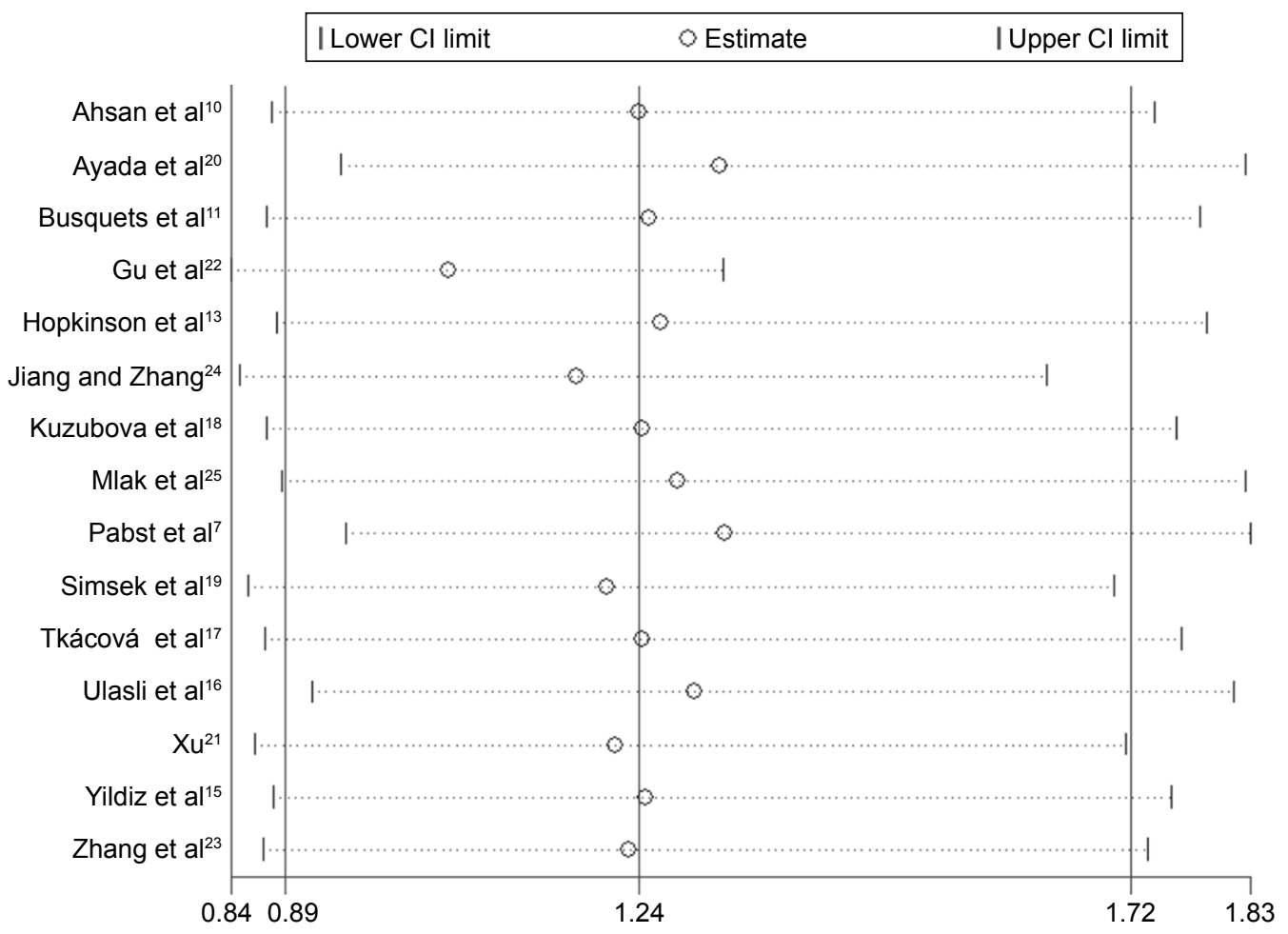

Figure 3 Sensitivity analysis for the association between the ACE polymorphism and COPD risk.

Abbreviation: $\mathrm{ACE}$, angiotensin-converting enzyme.

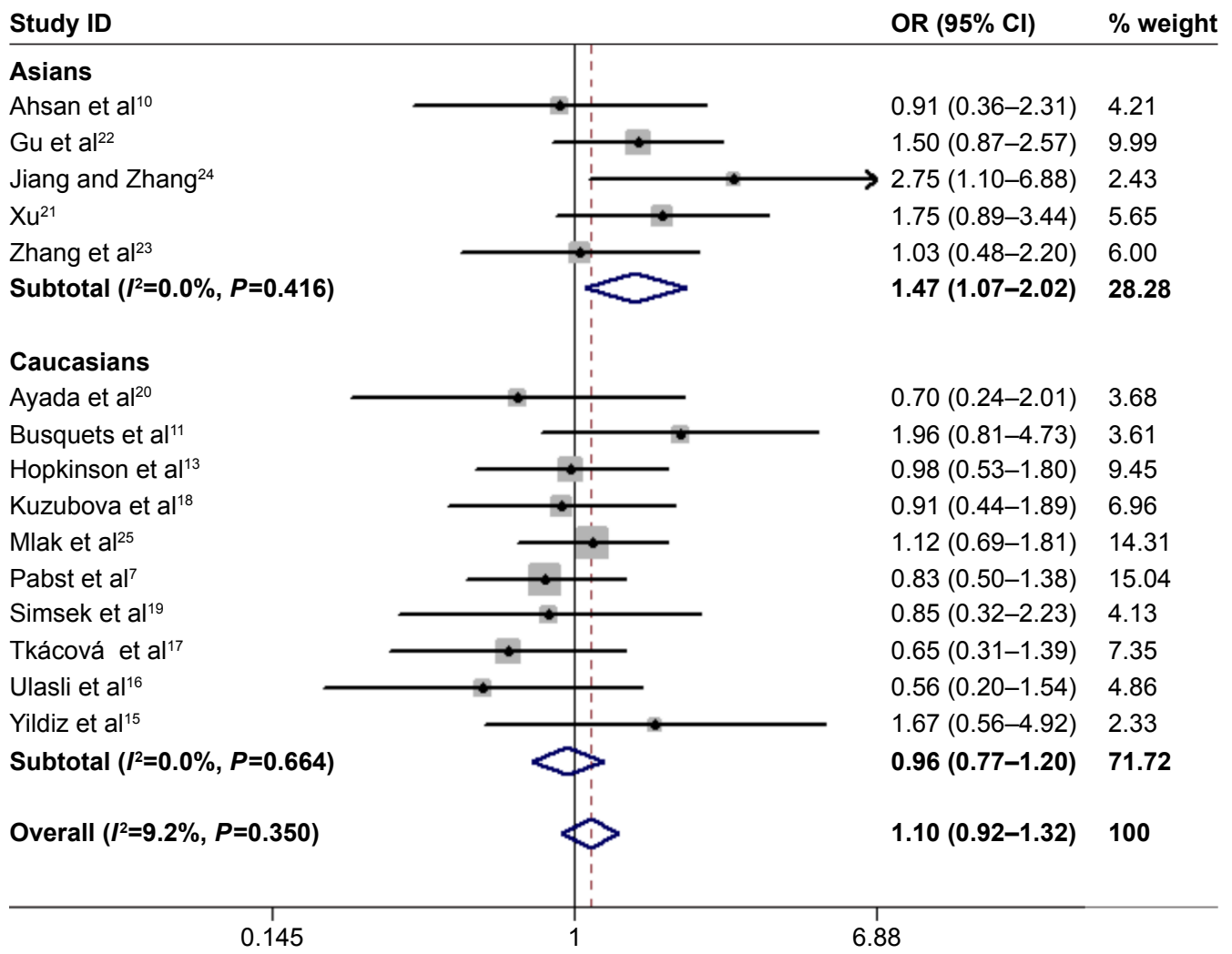

Figure 4 Forest plot for the association between ACE and COPD risk in dominant genetic model (DD+DI vs II). Abbreviations: $A C E$, angiotensin-converting enzyme; $O R$, odds ratio. 


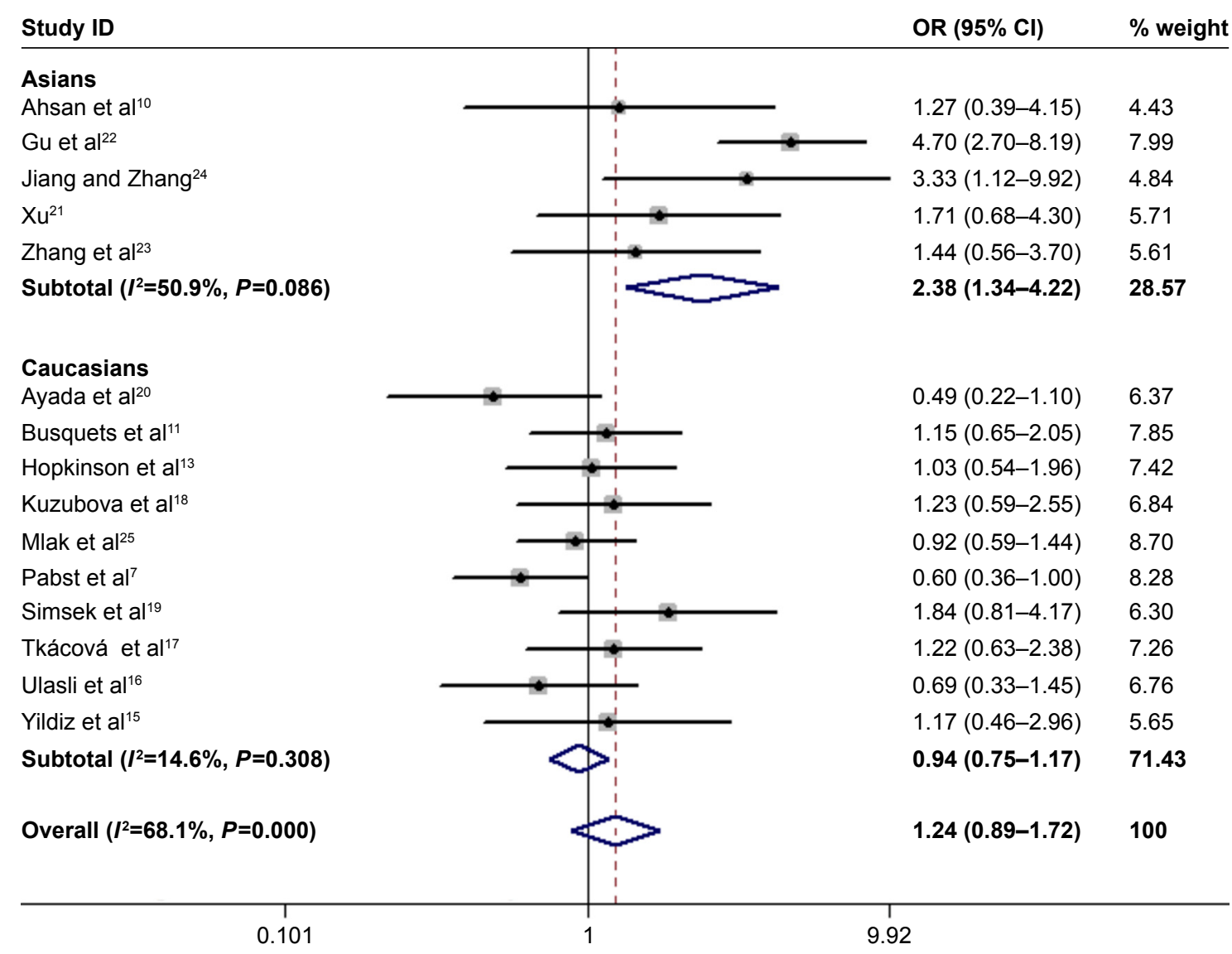

Figure 5 Forest plot for the association between ACE and COPD risk in recessive genetic model (DD vs DI+II). Note: Weights are from random-effects analysis.

Abbreviations: ACE, angiotensin-converting enzyme; OR, odds ratio.

(Figure 8). No publication bias was found in the funnel plot, Begg's test $(P=0.621)$, or Egger's test $(P=0.991)$.

\section{Association between ACE gene polymorphism and $\mathrm{PH}$}

The overall results of the present study detected no statistical significance between the $A C E$ gene polymorphism and the risk of $\mathrm{PH}$ in COPD patients. Interestingly, we found that the homozygote variant (DD) increased the risk of $\mathrm{PH}$ in Asian COPD patients (DD vs ID+II, OR=2.05, $P=0.05,95 \% \mathrm{CI}$ : 1.00-4.19; Figure 9).

\section{Discussion}

Many previous studies have revealed that the development and progression of COPD are affected by host genetic factors. ${ }^{10,16,26-29}$ Many researchers have reported the association between $A C E \mathrm{D}$ allele polymorphism and the susceptibility to COPD and COPD with PH., ${ }^{7,11,16,20}$ Unfortunately, some other results were inconclusive. ${ }^{15-17}$ Thus, we conducted a comprehensive meta-analysis to assess this relationship accurately.
The results of the meta-analysis indicated that the $A C E$ gene polymorphism was not associated with susceptibility to COPD in overall gene models. However, we found a significant heterogeneity between studies in the meta-analysis, which may be attributed to many factors, such as different demographic and genetic characteristics of Caucasian and Asian populations and the different quality of the included studies. Although the heterogeneity can be taken into account by conducting the random-effect model, it would increase the odds of type I error. To identify further reasons for the heterogeneity, we carried out a sensitivity analysis by sequentially excluding each study, and statistically similar results were obtained, suggesting the stability of the meta-analyses. Therefore, we performed a subgroup analysis to investigate the effect of ethnicity. Surprisingly, the subgroup analysis results showed that the $A C E$ gene polymorphism, especially the DD genotype, increased the risk of susceptibility to COPD in Asians, but not in Caucasians. Nevertheless, the studies on patients with COPD with $\mathrm{PH}$ involved in the meta-analysis were mainly carried out in China, as well as the studies were with small sample size. Therefore, the results should be interpreted cautiously and 


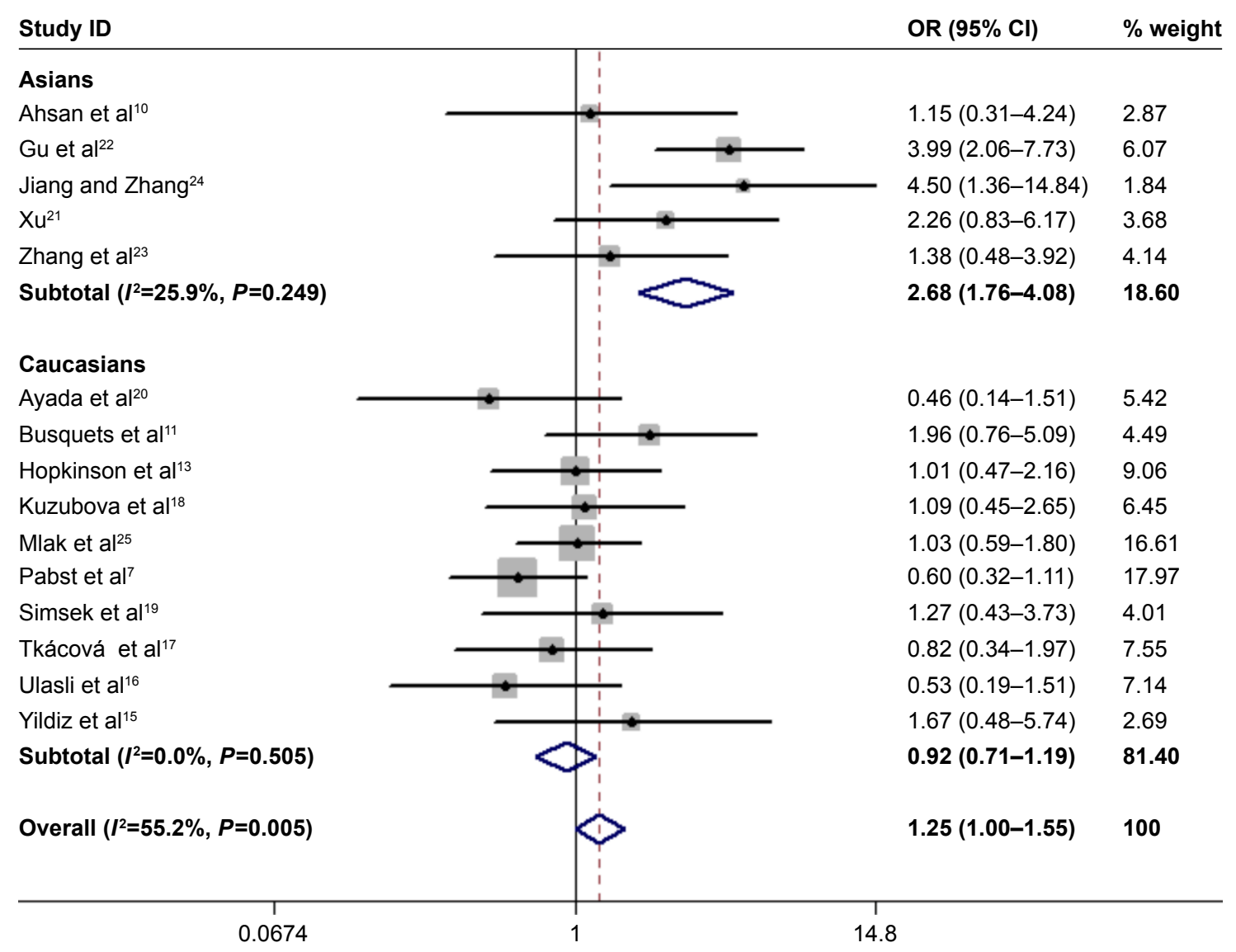

Figure 6 Forest plot for the association between ACE and COPD risk in codominant genetic model (DD vs II). Abbreviations: $A C E$, angiotensin-converting enzyme; $O R$, odds ratio.

studies with larger sample size should be carried out in future to confirm the conclusion derived from this study.

Compared with I allele, the D allele is associated with higher concentration and activity of circulating and tissue $A C E,^{7,13,30}$ which could have potential effects on pulmonary vascular inflammation, which is the central feature of COPD associated with lung remodeling, parenchymal destruction, and the development of emphysema. ${ }^{7,31}$ Peinado et al confirmed the presence of inflammatory changes in the pulmonary capillary bed in patients with mild COPD without hypoxemia. ${ }^{32}$ Tkacova and Joppa found that serum high-sensitivity $\mathrm{C}$-reactive protein increased from the homozygous II to the heterozygous ID and then to the homozygous DD $A C E$ genotype group, suggesting that the $A C E$ plays an important role in vascular micro-inflammation. ${ }^{33} \mathrm{ACE}$ catalyzes the conversion of AngI into AngII, which stimulates the release of cytokines such as monocyte chemotactic protein-1, and the latter has been shown to activate tissue mast cells in response to acute alveolar hypoxia, thereby triggering systemic inflammation. ${ }^{34}$ Wong et al found that the cytokine response mediated by AngII was inhibited by losartan, an AT1 receptor antagonist. ${ }^{35}$ Their findings, which are consistent with our results, can explain why the $A C E$ DD genotype increased the risk of COPD.

In addition, as a serious complication, $\mathrm{PH}$ develops in $30 \%-70 \%$ of patients with COPD, thereby increasing morbidity and mortality. ${ }^{36}$ The current study showed that the homozygote variant (DD) increased the risk of PH in COPD patients among Asians. The previous studies indicated that the main mechanisms involved in the increase in pulmonary artery pressure include vasoconstriction and pulmonary vascular remodeling. ${ }^{5,17,36}$ Increased endothelium expression of ACE in small intra-acinar arteries has been shown in primary or secondary $\mathrm{PH},{ }^{31}$ suggesting that increased ACE-induced AngII production contributes to $\mathrm{PH}$. Further, lowering the ACE level reduces $\mathrm{PH}$ by controlling vasoconstriction. ${ }^{37}$ A large retrospective study in elderly patients hospitalized for COPD exacerbation identified that the use of ACE inhibitor or angiotensin II receptor blocker, when controlling for demographics, comorbidities, and other medication, was significantly associated with a decreased 90-day mortality following their COPD hospital presentation. ${ }^{38}$ Moreover, a study found that the abovementioned effects were enhanced by the degradation of bradykinin, which mediated the release 


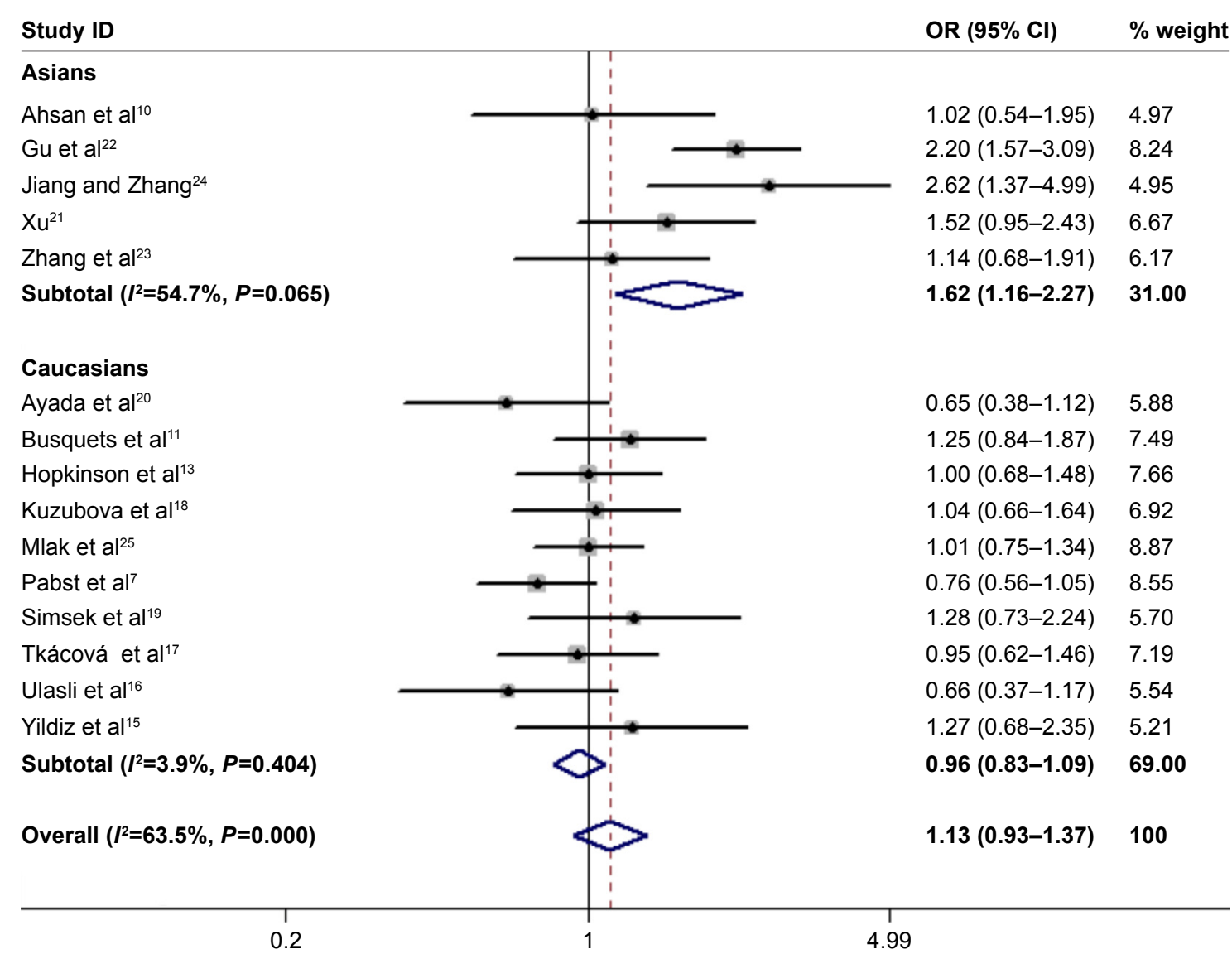

Figure 7 Forest plot for the association between ACE and COPD risk in allele genetic model ( $D$ vs I).

Note: Weights are from random-effects analysis.

Abbreviations: ACE, angiotensin-converting enzyme; OR, odds ratio.

of the vasodilator nitric oxide and prostaglandins. ${ }^{31}$ Olson et al suggested that the vasodilation effect of ACE inhibitor was improved through maximization of the bioavailability of bradykinin..$^{39}$ As previously mentioned, $A C E \mathrm{D}$ polymorphism is associated with a higher concentration and activity of

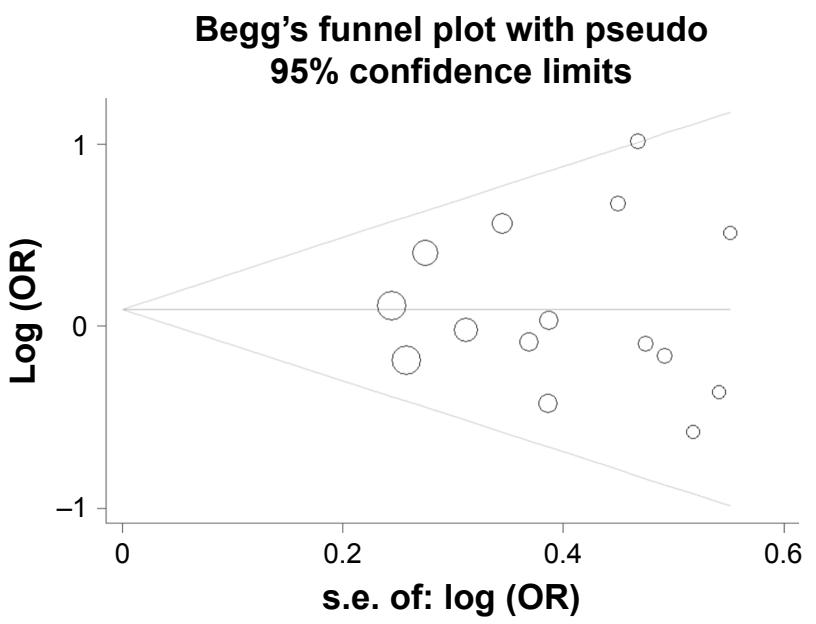

Figure 8 Funnel plot to test publication bias of studies under the dominant model (DD+DI vs II).

Abbreviations: OR, odds ratio; s.e., standard error. circulating and tissue ACE, which increases the predisposition to COPD with PH.

Interestingly, we also found no association of $A C E$ gene polymorphism with the risk of susceptibility to COPD or COPD with PH in Caucasians, whereas the D allele or DD genotype increased the risk of susceptibility to COPD and COPD with PH in Asians. Our finding is in accord with the studies of Li et al ${ }^{37}$ and Kanazawa et $a l,{ }^{40}$ respectively. Further, the sample size used for meta-analysis in our study is larger than that used in Li et al's study ${ }^{37}$ Moreover, we performed the subgroup analysis and the sensitivity analysis, and hence, our results are more reliable. Finally, we analyzed the association of $A C E$ polymorphism and COPD with $\mathrm{PH}$.

Additionally, there were several reasons that might have contributed to the different results between different ethnicities. First, different genetic backgrounds may account for the different results. Second, the different living environments of Asians and Caucasians may contribute to the different genetic effects. Third, the interaction with other predisposed gene polymorphism in different ethnicities may also be an influencing factor. Therefore, the recogni- 


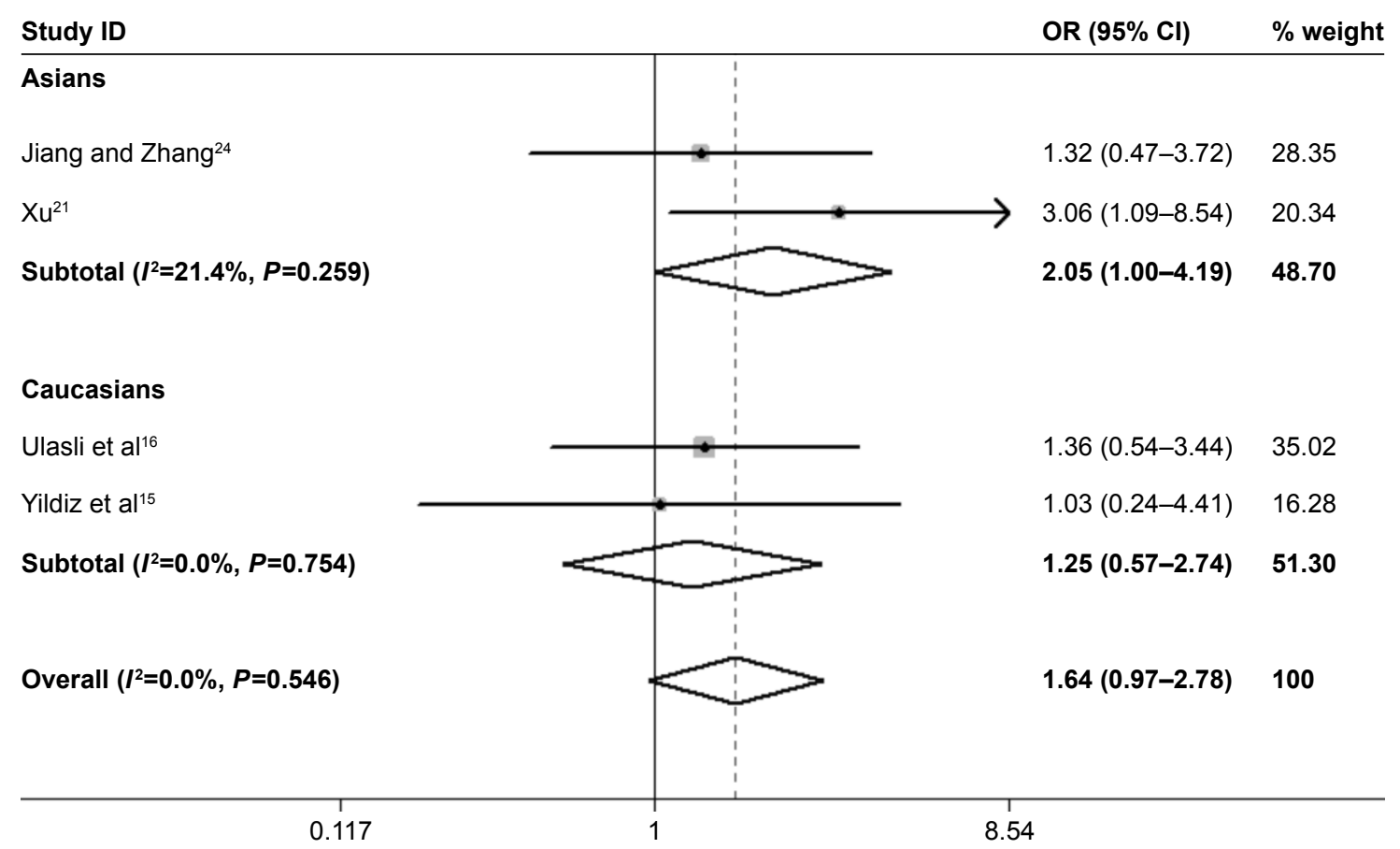

Figure 9 Forest plot for the association between $A C E$ and $\mathrm{PH}$ risk under recessive genetic model (DD vs DI+II). Abbreviations: $\mathrm{ACE}$, angiotensin-converting enzyme; $\mathrm{PH}$, pulmonary hypertension; OR, odds ratio.

tion of a genetic susceptibility to COPD and COPD with $\mathrm{PH}$ and identification of the $A C E$ polymorphism in the pathogenesis of COPD and COPD with PH could help us to predict the prognosis of COPD and influence our choice of treatment.

COPD is a complex disease which is influenced by the environment, genetic factors, and genotype-environment interactions. Cigarette smoking, ambient air pollution, underweight, infant respiratory infection, childhood chronic cough, parental history of respiratory diseases, low education, and early-life home overcrowding are risk factors for COPD. ${ }^{2,6}$ McCloskey et al found that there was a significant familial risk of airflow limitation observed in people who smoked and were siblings of patients with severe COPD, suggesting that genetics together with environmental factors could influence the susceptibility to COPD and PH. ${ }^{41}$ A study shows that the presence of the DD ACE genotype may increase the risk of smokers who are about to develop COPD.${ }^{11}$ Identification of the specific genes and the specific environmental factors that interact is of great interest in human genetics. For the complex respiratory disease, some environmental factors are important but are difficult to measure and it is not necessary to know the influences of specific gene and environment on a phenotype to determine if a genotype-environment interaction is present. ${ }^{42} \mathrm{In}$ addition, because of the lack of original information in the literatures, we could not extract environment-related data. In the future, more rigorous studies in which data will be stratified by other variables, such as smoking, ambient air pollution, age, and gender will be conducted to confirm the results.

\section{Limitations}

Some limitations of this meta-analysis should be considered. First, the subjects of the meta-analysis were Asians and Caucasians and there were no Africans recruited, so the conclusion is limited to Asian and Caucasian populations. Second, only studies included in the selected databases were included in our data analysis, and thus some relevant published or unpublished studies might have been missed. Third, because of the lack of original information on individuals, data were not stratified by other variables, such as gene-gene interaction, gene-environment interaction, and patients' gender and age.

\section{Conclusion}

The current meta-analysis suggests that $A C E$ gene polymorphism might be a risk factor in the pathogenesis of COPD and COPD with PH among Asians. We strongly recommend that in the future, researchers should design more rigorous and uniform case-control or cohort studies and include more ethnicities to confirm the results. 


\section{Acknowledgment}

This work was supported by the Department of Science and Technology of Sichuan Province (China) under Grant 2016FZ0082.

\section{Disclosure}

The authors report no conflicts of interest in this work.

\section{References}

1. López-Campos JL, Tan W, Soriano JB. Global burden of COPD. Respirology. 2016;21(1):14-23.

2. GOLD Reports 2018. Available from: http://goldcopd.org/gold-reports/. Accessed May 8, 2018.

3. Lozano R, Naghavi M, Foreman K, et al. Global and regional mortality from 235 causes of death for 20 age groups in 1990 and 2010: a systematic analysis for the Global Burden of Disease Study 2010. Lancet. 2012;380(9859):2095-2128.

4. Vos T, Flaxman AD, Naghavi M, et al. Years lived with disability (YLDs) for 1160 sequelae of 289 diseases and injuries 1990-2010: a systematic analysis for the Global Burden of Disease Study 2010. Lancet. 2012;380(9859):2163-2196.

5. Tanabe N, Amano S, Tatsumi K, et al. Angiotensin-converting enzyme gene polymorphisms and prognosis in chronic thromboembolic pulmonary hypertension. Circ J. 2006;70(9):1174-1179.

6. Wang C, Xu J, Yang L, et al. Prevalence and risk factors of chronic obstructive pulmonary disease in China (the China Pulmonary Health [CPH] study): a national cross-sectional study. Lancet. 2018;391(10131): 1706-1717.

7. Pabst S, Theis B, Gillissen A, et al. Angiotensin-converting enzyme I/D polymorphism in chronic obstructive pulmonary disease. Eur J Med Res. 2009;14 Suppl 4:177-181.

8. Cigarette smoking and health. American Thoracic Society. Am J Respir Crit Care Med. 1996;153(2):861-865.

9. Eisner MD, Anthonisen N, Coultas D, et al. An official American Thoracic Society public policy statement: novel risk factors and the global burden of chronic obstructive pulmonary disease. Am J Respir Crit Care Med. 2010;182(5):693-718.

10. Ahsan A, Ram R, Baig MA, Pasha MAQ. ACE I allele and eNOS $\mathrm{G}$ allele crosstalk may have a role in chronic obstructive pulmonary disease. Clin Biochem. 2004;37(11):1037-1040.

11. Busquets X, Macfarlane NG, Heinesuñer D, et al. Angiotensin-convertingenzyme gene polymorphisms, smoking and chronic obstructive pulmonary disease. Int J Chron Obstruct Pulmon Dis. 2007;2(3):329.

12. Andreas S, Herrmannlingen C, Raupach T, et al. Angiotensin II blockers in obstructive pulmonary disease: a randomised controlled trial. Eur Respir J. 2006;28(3):972-979.

13. Hopkinson NS, Nickol AH, Payne J, et al. Angiotensin converting enzyme genotype and strength in chronic obstructive pulmonary disease. Am J Respir Crit Care Med. 2004;170(4):395-399.

14. Forth R, Montgomery H. ACE in COPD: a therapeutic target? Thorax. 2003;58(7):556-558

15. Yildiz P, Oflaz H, Cine N, Erginelunaltuna N, Erzengin F, Yilmaz V. Gene polymorphisms of endothelial nitric oxide synthase enzyme associated with pulmonary hypertension in patients with COPD Respir Med. 2003;97(12):1282.

16. Ulasli SS, Eyuboglu FO, Verdi H, Atac FB. Associations between endothelial nitric oxide synthase $\mathrm{A} / \mathrm{B}$, angiotensin converting enzyme $\mathrm{I} / \mathrm{D}$ and serotonin transporter $\mathrm{L} / \mathrm{S}$ gene polymorphisms with pulmonary hypertension in COPD patients. Mol Biol Rep. 2013;40(10): $5625-5633$.

17. Tkácová R, Joppa P, Stancák B, Salagovic J, Misíková S, Kalina I. The link between angiotensin-converting enzyme genotype and pulmonary artery pressure in patients with COPD. Wien Klin Wochenschr. 2005;117(5-6):210-214
18. Kuzubova NA, Chukhlovin AB, Morozova EB, Totolian AA, Titova ON Common intronic $\mathrm{D}$ variant of $A C E$ gene is associated with endothelial dysfunction in COPD. Respir Med. 2013;107(8):1217-1221.

19. Simsek S, Tekes S, Oral D, et al. The insertion/deletion polymorphism in the $A C E$ gene and chronic obstructive pulmonary disease. Genet $M o l$ Res. 2013;12(2):1392.

20. Ayada C, Toru U, Yerlikaya A, Sahin S, Turgut S, Turgut G. Evaluation of whether the $A C E$ gene I/D polymorphism constitutes a risk factor for chronic obstructive pulmonary disease in the Turkish population. Genet Mol Res. 2014;13(4):10427-10433.

21. Xu H. [Relationship Between Angiotensin-Converting Enzyme Gene Polymorphism and Pathogenesis of Chronic Obstructive Pulmonary Heart Disease]. Shanghai: Fudan University; 2002. Chinese.

22. Gu H, Zhang H, Yang L. [Relationship between angiotensin-converting enzyme gene polymorphism and susceptibility to chronic obstructive pulmonary disease]. Basic Med Sci Clin. 2003;23(2):174-177. Chinese [with English abstract].

23. Zhang X, Wang C, Dai H, Lin Y, Zhang J. Association between angiotensin-converting enzyme gene polymorphisms and exercise performance in patients with COPD. Respirology. 2008;13(5):683.

24. Jiang $\mathrm{C}$, Zhang $\mathrm{N}$. [The study of the relationship of ACE and gene polymorphism (I/D)]. Foreign Med Sci. 2002;23(4):248-249. Chinese [with English abstract].

25. Mlak R, Homa-Mlak I, Powrózek T, et al. Impact of I/D polymorphism of $A C E$ gene on risk of development and course of chronic obstructive pulmonary disease. Arch Med Sci. 2016;12(2):279-287.

26. Hopkinson NS, Eleftheriou KI, Payne J, et al. +9/+9 Homozygosity of the bradykinin receptor gene polymorphism is associated with reduced fat-free mass in chronic obstructive pulmonary disease. Am J Clin Nutr. 2006;83(4):912-917.

27. Hopkinson NS, Li KW, Kehoe A, et al. Vitamin D receptor genotypes influence quadriceps strength in chronic obstructive pulmonary disease. Am J Clin Nutr. 2008;87(2):385-390.

28. Wei W, Ping L, Chen YF, Yang J. Association between $\beta 2$-adrenergic receptor-16Arg/Gly gene polymorphism and chronic obstructive pulmonary disease risk: systematic review and meta-analysis. Iran J Public Health. 2014;43(7):877-888.

29. Wang CD, Chen N, Huang L, et al. Impact of CYP1A1 polymorphisms on susceptibility to chronic obstructive pulmonary disease: a metaanalysis. Biomed Res Int. 2015;2015(3):1-9.

30. Moskowitz DW. From pharmacogenomics to improved patient outcomes: angiotensin I-converting enzyme as an example. Diabetes Technol Ther. 2002;4(4):519-532.

31. Srikrishna D, Astin R, Kemp PR, Hopkinson NS. Renin-angiotensin system blockade: a novel therapeutic approach in chronic obstructive pulmonary disease. Clin Sci. 2012;123(8):487-498.

32. Peinado VI, Barberá JA, Abate P, et al. Inflammatory reaction in pulmonary muscular arteries of patients with mild chronic obstructive pulmonary disease. Am J Resp Crit Care Med. 1999;159(5 Pt 1):1605.

33. Tkacova R, Joppa P. Angiotensin-converting enzyme genotype and C-reactive protein in patients with COPD. Eur Respir J. 2007; 29(4):816

34. Jie C, Donham P, Rooijen NV, Wood JG, Gonzalez NC. Monocyte chemoattractant protein-1 released from alveolar macrophages mediates the systemic inflammation of acute alveolar hypoxia. Am J Respir Cell Mol Biol. 2011;45(1):53-61.

35. Wong MH, Chapin OC, Johnson MD. LPS-stimulated cytokine production in type I cells is modulated by the renin-angiotensin system. Am J Respir Cell Mol Biol. 2012;46(5):641-650.

36. Shaw JG, Dent AG, Passmore LH, et al. Genetic influences on right ventricular systolic pressure (RVSP) in chronic obstructive pulmonary disease (COPD). BMC Pulm Med. 2012;12(1):25.

37. Li W, Lan F, Yan F, Shen H. Angiotensin-converting enzyme I/D polymorphism is associated with COPD risk in Asian population: evidence from a meta-analysis. COPD. 2013;10(1):35-39.

38. Mortensen EM, Copeland LA, Pugh MJ, et al. Impact of statins and ACE inhibitors on mortality after COPD exacerbations. Respir Res. 2009; 10(1):45. 
39. Olson TP, Frantz RP, Turner ST, Bailey KR, Wood CM, Johnson BD. Gene variant of the bradykinin B2 receptor influences pulmonary arterial pressures in heart failure patients. Clin Med Circ Respirat Pulm Med. 2009;2009(3):9-17.

40. Kanazawa H, Okamoto T, Hirata K, Yoshikawa J. Deletion polymorphisms in the angiotensin converting enzyme gene are associated with pulmonary hypertension evoked by exercise challenge in patients with chronic obstructive pulmonary disease. Am J Respir Crit Care Med. 2000;162(1):1235-1238.
41. McCloskey SC, Patel BD, Hinchliffe SJ, Reid ED, Wareham NJ, Lomas DA. Siblings of patients with severe chronic obstructive pulmonary disease have a significant risk of airflow obstruction. Am J Respir Crit Care Med. 2001;164(8):1419-1424.

42. Sandford AJ, Silverman EK. Chronic obstructive pulmonary disease. 1: Susceptibility factors for COPD the genotype-environment interaction. Thorax. 2002;57(8):736-741.

\section{Publish your work in this journal}

The International Journal of COPD is an international, peer-reviewed journal of therapeutics and pharmacology focusing on concise rapid reporting of clinical studies and reviews in COPD. Special focus is given to the pathophysiological processes underlying the disease, intervention programs, patient focused education, and self management protocols.

\section{Dovepress}

This journal is indexed on PubMed Central, MedLine and CAS. The manuscript management system is completely online and includes a very quick and fair peer-review system, which is all easy to use. Visit http://www.dovepress.com/testimonials.php to read real quotes from published authors.

Submit your manuscript here: http://www.dovepress.com/international-journal-of-chronic-obstructive-pulmonary-disease-journal 